\title{
Design of a 2 GHz Linear-in-dB Variable-Gain Amplifier with 80-dB Gain Range
}

\author{
Zhengyu Sun and Yuepeng Yan \\ Institute of Microelectronics of Chinese Academy of Sciences, Beijing 100029, China \\ Correspondence should be addressed to Zhengyu Sun; szy7888@gmail.com
}

Received 11 January 2014; Revised 21 March 2014; Accepted 31 March 2014; Published 17 April 2014

Academic Editor: Egidio Ragonese

Copyright (C) 2014 Z. Sun and Y. Yan. This is an open access article distributed under the Creative Commons Attribution License, which permits unrestricted use, distribution, and reproduction in any medium, provided the original work is properly cited.

\begin{abstract}
A broadband linear-in- $\mathrm{dB}$ variable-gain amplifier (VGA) circuit is implemented in $0.18 \mu \mathrm{m}$ SiGe BiCMOS process. The VGA comprises two cascaded variable-gain core, in which a hybrid current-steering current gain cell is inserted in the Cherry-Hooper amplifier to maintain a broad bandwidth while covering a wide gain range. Postlayout simulation results confirm that the proposed circuit achieves a $2 \mathrm{GHz} 3-\mathrm{dB}$ bandwidth with wide linear-in- $\mathrm{dB}$ gain tuning range from $-19 \mathrm{~dB}$ up to $61 \mathrm{~dB}$. The amplifier offers a competitive gain bandwidth product of $2805 \mathrm{GHz}$ at the maximum gain for a 110-GHz f $\mathrm{fiCMOS}_{t}$ technology. The amplifier core consumes $31 \mathrm{~mW}$ from a $3.3 \mathrm{~V}$ supply and occupies active area of $280 \mu \mathrm{m}$ by $140 \mu \mathrm{m}$.
\end{abstract}

\section{Introduction}

The telecommunication industry continues to drive forward with gigabit-class high-speed data transmission in microwave, millimeter-wave, and optical communication systems. Higher data rate transmission requires wider bandwidth and larger dynamic range for the receiver system. For example in the $60 \mathrm{GHz}$ standards such as IEEE 802.11ad [1], the spectrum is about $2 \mathrm{GHz}$. And the signal strength at the receiver input can change dramatically which is common in short-range wireless systems. VGA as a key component in the automatic gain control (AGC) loop provides constant signal strength to the baseband processor to maximize the dynamic range of the receiver system and compensates gain variations caused by process, voltage, and temperature (PVT) variations. Research in SiGe and CMOS circuits in the broadband VGA is an active topic in optical, wireline, and millimeterwave receivers [2-6]. Among various broadband techniques, Cherry-Hooper amplifier [7] has had numerous applications in AGC and limiting amplifiers. Solutions employing CherryHooper amplifier [8] can achieve a 3-dB bandwidth above $2 \mathrm{GHz}$ and satisfy bandwidth requirements such as $60 \mathrm{GHz}$ short-range wireless systems. However, their gain range is not sufficient to meet the target of more than $80 \mathrm{~dB}$ if additional margin is needed for the receiver. Moreover, a linear-in- $\mathrm{dB}$ control signal for VGA will simplify the system level design for AGC.

In this paper, a VGA circuit is presented for high-speed data communication systems. In Section 2, a new variable gain core is designed by combining a hybrid current-steering cell with the Cherry-Hooper amplifier. Section 3 describes the VGA system which is made up of variable gain core introduced in Section 2 and other circuits. Section 4 shows the postlayout simulation results. Finally, Section 5 draws the conclusions.

\section{Variable Gain Core Design}

The schematic of the proposed variable gain core is shown in Figure 1. In order to maintain a broad bandwidth while covering a wide gain range, a hybrid current-steering (HCS) current gain cell is inserted in the Cherry-Hooper amplifier. The HCS cell is featured with a constant DC current output and an ability to have same AC characteristics with classical current-steering (CS) cell. The gain is varied through only the HCS cell without degrading the broadband characteristic of Cherry-Hooper amplifier with constant gain.

2.1. Broadband Amplifier Topology. If the current gain cell is removed from the gain core shown in Figure 1 the topology 


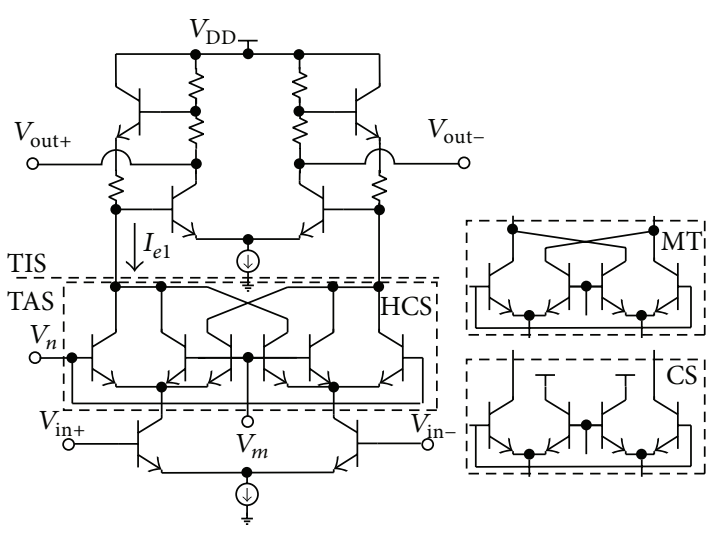

FIGURE 1: Proposed variable gain core with hybrid current-steering cell.

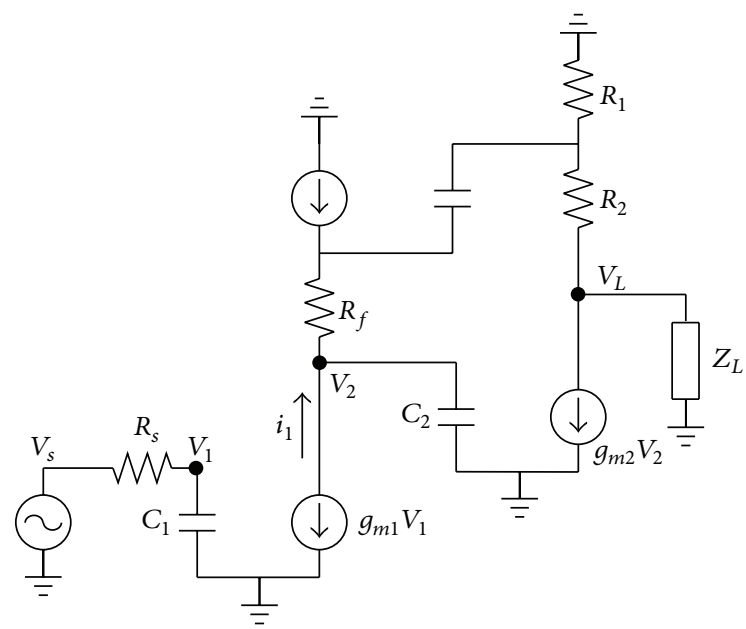

FIGURE 2: Small signal equivalent circuit for the TAS-TIS combination.

is a differential Cherry-Hooper $(\mathrm{CH})$ amplifier with emitterfollower feedback [9]. The Cherry-Hooper amplifier is a cascading combination of a transadmittance stage (TAS) with a transimpedance stage (TIS). The strong mismatch between the two stages results in a large bandwidth [7]. This topology has the advantage of extending the bandwidth by moving the dominant poles from lower pole determined by load capacitance and the output resistance to the much higher poles. The shunt-shunt feedback employs an emitter follower which isolates the bias currents through the TAS and TIS. Both the emitter follower and the resistor in the feedback loop help to raise the gain at high frequency.

Because of the symmetry, the differential Cherry-Hooper amplifier with emitter-follower feedback can be analyzed through single-ended part. Figure 2 is the small signal equivalent circuit for the TAS-TIS combination including major parasitic parameter. Since the TIS is usually followed by transconductor stage or emitter follower, the load of Cherry-Hooper amplifier can be approximately assumed to be a capacitor $C_{L}$. Thus, the input impedance of TIS stage can be derived as

$$
\begin{aligned}
Z_{\text {in }}=\frac{v_{2}}{i_{1}}= & \frac{R_{f}}{1+g_{m 2} R_{1}} \\
& \cdot\left(\left(1+s C_{L}\left(R_{1}+R_{2}\right)\right)\right. \\
& \times\left(1+\frac{C_{2} R_{f}+C_{L}\left(R_{1}+R_{2}\right)}{1+g_{m 2} R_{1}} s\right. \\
& \left.\left.\quad+\frac{C_{2} C_{L} R_{f}\left(R_{1}+R_{2}\right)}{1+g_{m 2} R_{1}} s^{2}\right)^{-1}\right) .
\end{aligned}
$$
as

The transimpedance gain of TIS stage can also be derived

$$
Z_{t}=\frac{v_{L}}{i_{1}}=-\frac{g_{m 2}}{C_{2} C_{L}\left(s^{2}+\left(w_{0} / Q\right) s+w_{0}^{2}\right)},
$$

where

$$
\begin{aligned}
& w_{0}=\sqrt{\frac{1+g_{m 2} R_{1}}{C_{2} C_{L} R_{f}\left(R_{1}+R_{2}\right)}}, \\
& Q=\sqrt{\frac{C_{2} C_{L} R_{f}\left(R_{1}+R_{2}\right)\left(1+g_{m 2} R_{1}\right)}{\left(C_{2} R_{f}+C_{L} R_{1}+C_{L} R_{2}\right)^{2}}} .
\end{aligned}
$$

From (2) and (3), there is a trade-off between DC gain and bandwidth through resistors $R_{f}$ and $R_{2}$. Increasing $R_{2}$ or $R_{f}$ will raise the $\mathrm{DC}$ gain while reducing bandwidth.

From (1), the input impedance of TIS stage is $(1+$ $\left.g_{m 2} R_{1}\right)$ times less than $R_{f}$ and is relatively low impedance compared to the output impedance of TAS stage. Therefore, the overall voltage gain of TAS-TIS combination can be approximately seen as the product of transadmittance gain and transimpedance gain as

$$
A_{v}=\frac{v_{L}}{v_{s}}=\frac{i_{1}}{v_{s}} \cdot \frac{v_{L}}{i_{1}}=G_{m} Z_{t},
$$

with the transadmittance gain as

$$
G_{m}=\frac{i_{1}}{v_{s}}=\frac{g_{m 1}}{1+s C_{1} R_{s}},
$$

where $R_{s}$ is the output impedance of preceding stage.

Since the input impedance of TAS stage is usually much larger than the $R_{s}$, the pole of TAS stage is much larger than of TIS stage. Therefore, the dominant pole of the CherryHooper amplifier is mostly contributed by the poles of TIS stage.

The output impedance of TIS stage can also be derived as

$$
Z_{\text {out }}=\frac{R_{1}+R_{2}}{1+g_{m 2} R_{1}} \cdot \frac{1+s C_{2} R_{f}}{1+s\left(C_{2} R_{f} /\left(1+g_{m 2} R_{1}\right)\right)},
$$




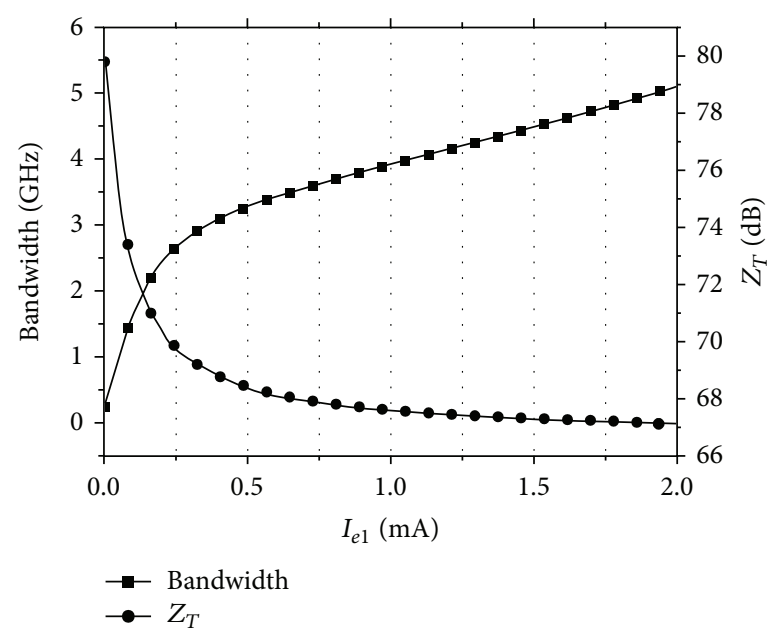

FIgURE 3: Transimpedance gain and its bandwidth versus bias current $I_{e 1}$.

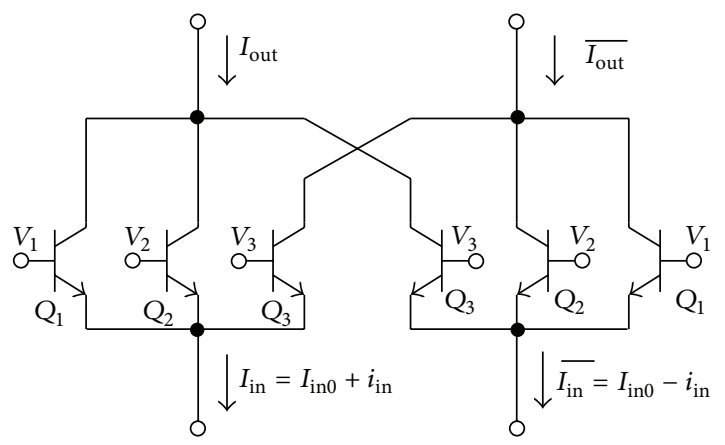

FIGURE 4: Generalized hybrid current-steering current gain cell.

which shows relatively low impedance that can drive the following stage.

For broadband amplifier design, the bias currents through the TAS and TIS are constant to maintain the transistors biased at near peak $f_{t}$ current density. Then the desired gain and bandwidth are determined by the resistors in the feedback and load. If the DC current $I_{e 1}$ in the TAS changed, the frequency response of the TIS will be changed as well since the bias conditions of transistors in emitter-follower and TIS are changed. Figure 3 shows the transimpedance gain between output voltage and current flowing out of TAS with its 3-dB bandwidth at different bias DC current $I_{e 1}$. Decreasing the DC current $I_{e 1}$, the bandwidth will decrease while the gain will increase. Such effect is detrimental to the integrity design of the Cherry-Hooper amplifier.

2.2. Current Gain Cell. There are two commonly used current gain cells as shown on the right side of Figure 1: currentsteering (CS) cell and multiplier (MT) cell. The currentsteering cell has better dynamic range performance but its DC output current is not constant. The multiplier cell has constant DC output level due to the cross coupling of the quad

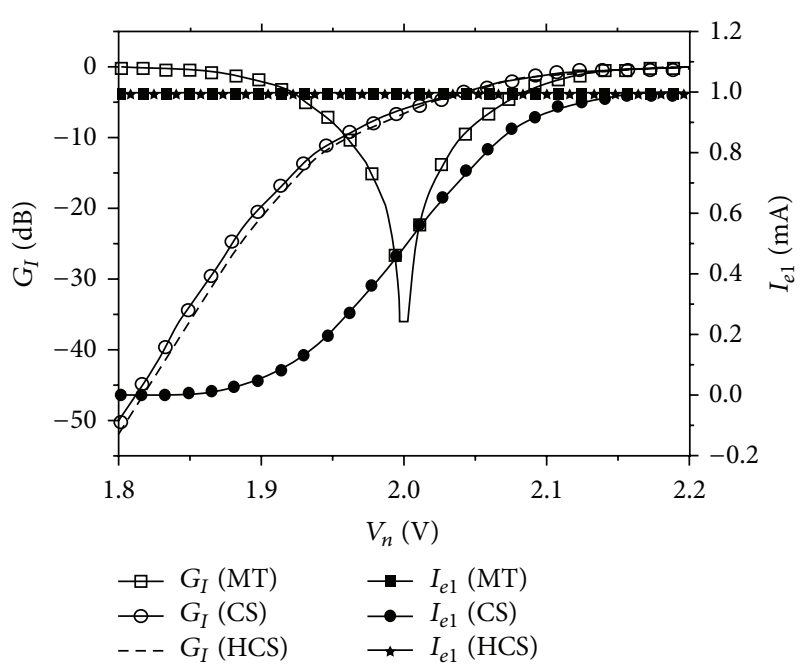

FIgURE 5: Comparison of current gain and DC current output $I_{e 1}$ of MT, CS and HCS cell.

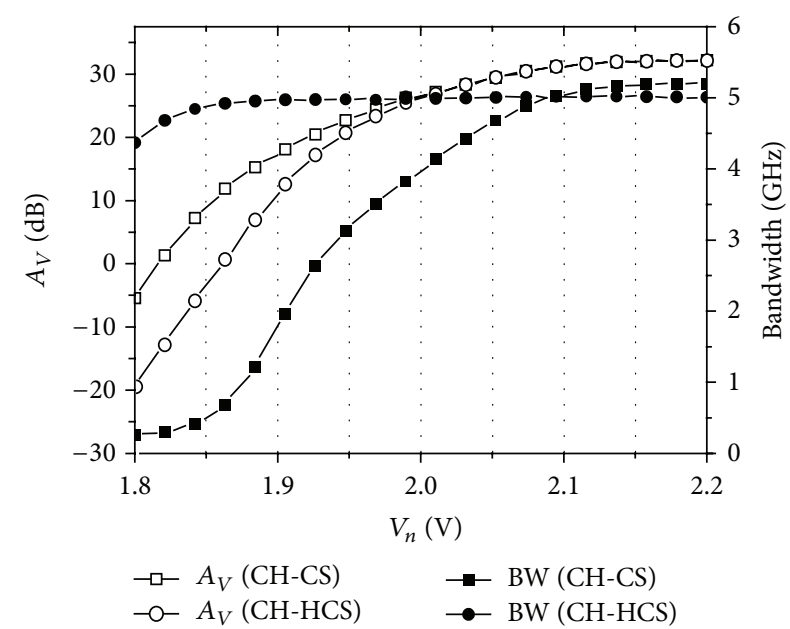

FIGURE 6: Comparison of voltage gain and its bandwidth of CherryHooper amplifier with CS and HCS cell.

collectors but its gain polarity will change at certain control voltage leading to a limited tuning range.

In order to maintain the broadband characteristics of the Cherry-Hooper amplifier while covering a wide gain range, a hybrid current-steering current gain cell is employed to change gain while having the least influence to the CherryHooper amplifier. A generalized hybrid current-steering cell is shown in Figure 4. The cell is symmetrical about the $y$-axis, thus the DC current output is equal to the DC current input. The output current coming out of the cell is related to the input current as follows:

$$
\begin{aligned}
I_{\text {out }} & =\left(\alpha_{1}+\alpha_{2}\right)\left(I_{\text {in } 0}+i_{\text {in }}\right)+\alpha_{3}\left(I_{\text {in } 0}-i_{\text {in }}\right) \\
& =I_{\text {in } 0}+\left(\alpha_{1}+\alpha_{2}-\alpha_{3}\right) i_{\text {in }}
\end{aligned}
$$




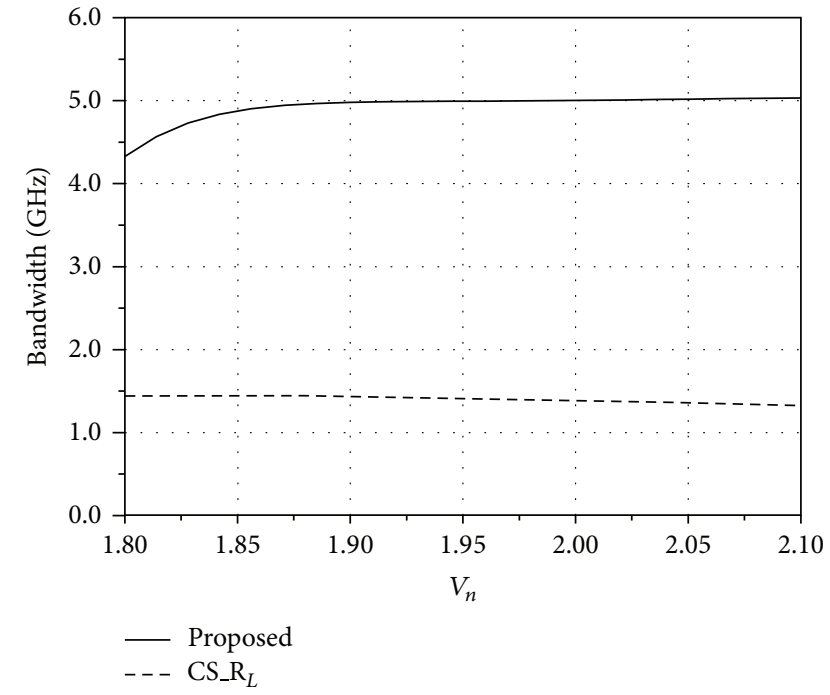

(a)

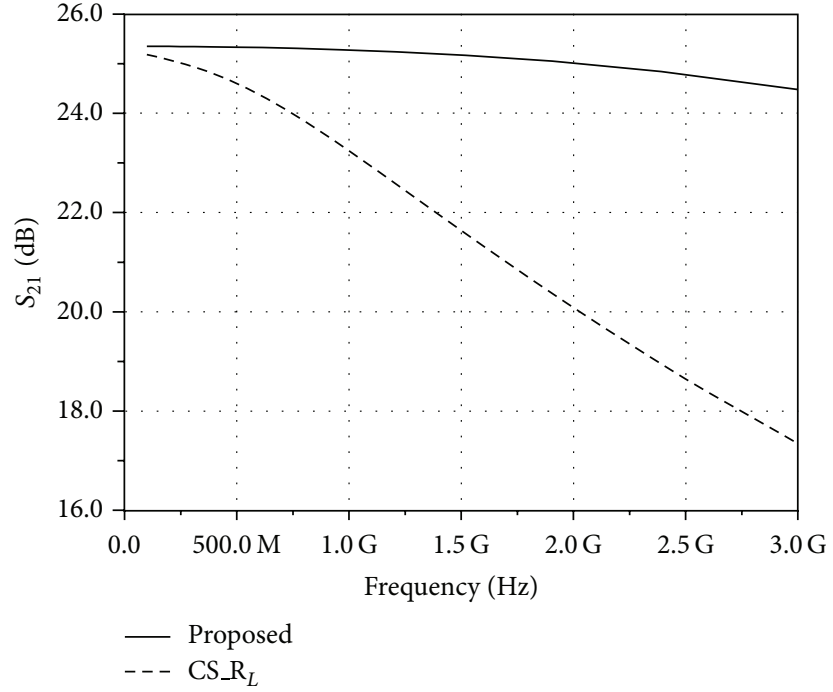

(b)

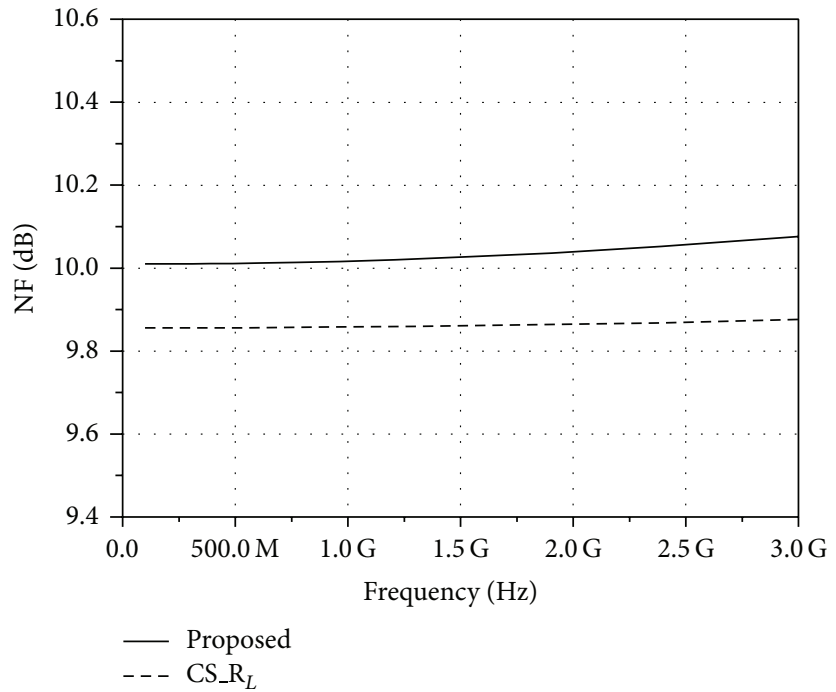

(c)

FIgURE 7: Comparison between proposed CH-HCS cell and CS- $\mathrm{R}_{L}$ cell.

where $\alpha_{n}$ is the current proportion of the $n$th branch dependent on transistor size and bias voltage as follows:

$$
\alpha_{n}=\frac{1}{\sum_{i=1}^{3}\left(I_{0 i} / I_{0 n}\right) \exp \left(\left(V_{i}-V_{n}\right) / V_{T}\right)} .
$$

Thus the current gain is expressed as

$$
G_{I}=\alpha_{1}+\alpha_{2}-\alpha_{3} .
$$

In the proposed VGA, a special case with equal $V_{2}$ and $V_{3}$ voltage and transistor size arrangement as $Q_{1}: Q_{2}: Q_{3}=2: 1: 1$ [10] is employed with current gain derived from (9) and (10) as follows:

$$
G_{I}=\alpha_{1}=\frac{1}{1+\exp \left(\left(V_{2}-V_{1}\right) / V_{T}\right)} .
$$

The current gain expression of the hybrid currentsteering cell is the same as the conventional current-steering cell, which implies that the same linear- $\mathrm{dB}$ technology for CS cell can also be used for HCS cell. Figure 5 compares the current gain and DC output current of the three current gain cells: CS, MT, and HCS. The HCS cell has the same wide gaintuning ability as CS cell while having a constant DC output current as MT cell.

2.3. Broadband Variable Gain Core. The strong impedance mismatch between gain stages for broadband technique is maintained with the insertion of hybrid current-steering cell in the middle of the Cherry-Hooper amplifier. The transadmittance stage is composed of the input transconductance amplifier and the hybrid current-steering cell, which has a high input and high output impedance. It is followed by the 


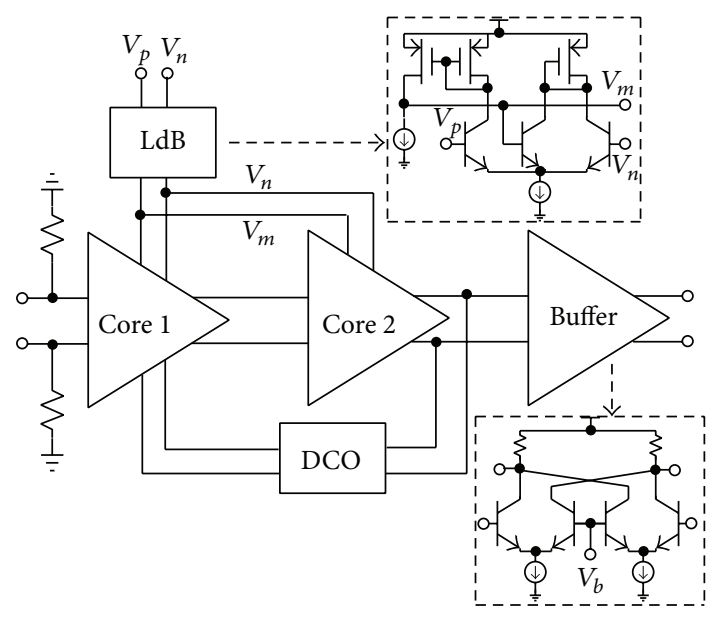

FIGURE 8: Block diagram of proposed VGA system.

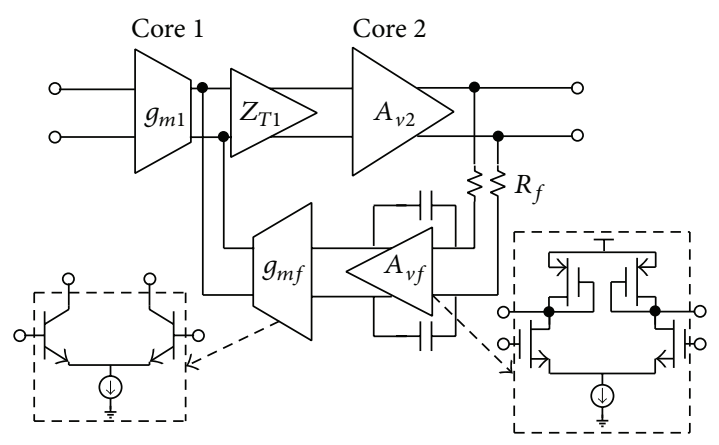

FIGURE 9: Block diagram of DC offset correction circuit.

transimpedance stage which has low input and low output impedance. The bias current of the input transconductance amplifier is reused by the HCS cell and the emitter follower in the feedback path. Since the current gain cell operates as common-base amplifier, the bandwidth of it is much wider than that of the Cherry-Hooper amplifier. Thus the dominant poles of Cherry-Hooper amplifier still dominate the 3-dB bandwidth of the variable gain core and can be optimized to strike a balance between characteristics such as gain, bandwidth, gain flatness, and group delay using guidelines [9].

To show the advantage of the proposed structure, another structure with only difference in that its current gain cell was replaced with a current-steering cell was also designed. Figure 6 shows the comparison of the Cherry-Hooper amplifiers inserted with hybrid current-steering (CH-HCS) cell and with current-steering (CH-CS) cell. The $3-\mathrm{dB}$ bandwidth of the $\mathrm{CH}$-CS cell decreases rapidly with decreasing control voltage, while the bandwidth of $\mathrm{CH}-\mathrm{HCS}$ cell maintains being flat above $4 \mathrm{GHz}$ in spite of control voltage changing. Moreover, the relationship between gain and control voltage of $\mathrm{CH}-\mathrm{CS}$ cell is deviated from the $\mathrm{CH}-\mathrm{HCS}$ cell at low gain range due to the transimpedance gain increases as indicated in Figure 3.

In order to further show the advantage of the proposed $\mathrm{CH}$-HCS cell over traditional current-steering type VGA

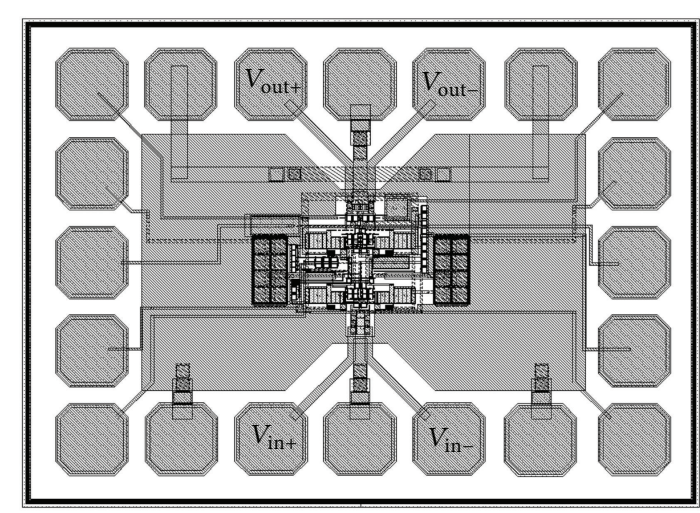

Figure 10: Layout of the VGA.

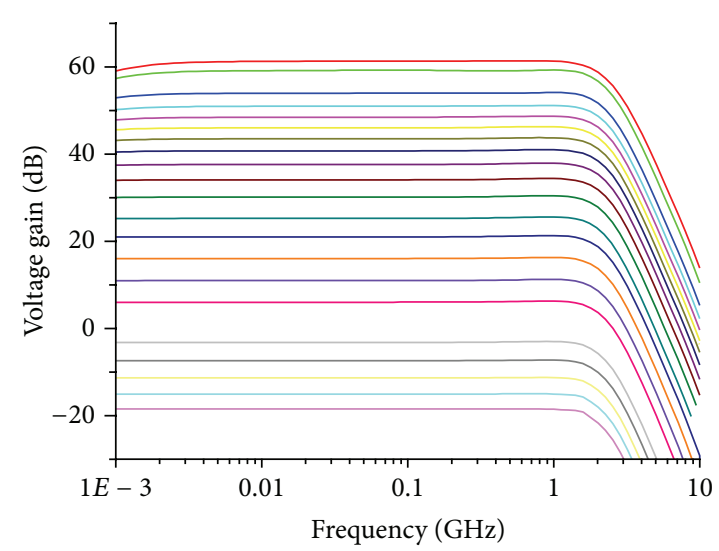

FIGURE 11: Frequency response versus various control voltage $V_{p}$.

with load resistor $\mathrm{R}_{L}\left(\mathrm{CS}-\mathrm{R}_{L}\right)$, a CS- $\mathrm{R}_{L}$ cell of the same DC current consumption and peak gain as the CH-HCS cell is designed. The $3-\mathrm{dB}$ bandwidth varying with control voltage is compared in Figure 7(a), which shows that a threefold GBW can be achieved using CH-HCS cell. Figures $7(\mathrm{~b})$ and $7(\mathrm{c})$ compare the $S_{21}$ and noise figure at the maximum gain, which shows a similar noise performance and wider GBW for the $\mathrm{CH}-\mathrm{HCS}$ cell over traditional CS- $\mathrm{R}_{L}$ cell.

\section{VGA Architecture}

The proposed VGA architecture is shown in Figure 8. In order to obtain a gain range over $70 \mathrm{~dB}$, two cascaded stages of variable gain core mentioned in Section 2 are employed with each providing about $40-\mathrm{dB}$ gain range. Since the transadmittance and transimpedance stages in one gain core have independent bias currents and allow a dc-coupled output, the first core in cascaded stages behaves as an output buffer to the second core which can eliminate the DC blocking capacitor. For testing purposes, $50 \mathrm{ohm}$ resistors are placed at the differential inputs for input matching and a high-speed $\mathrm{f}_{\mathrm{t}}$ doubler output buffer is used at the output.

In order to reduce DC offsets due to component mismatch, a differential feedback loop is designed with its schematic shown in Figure 9. The differential output voltage 


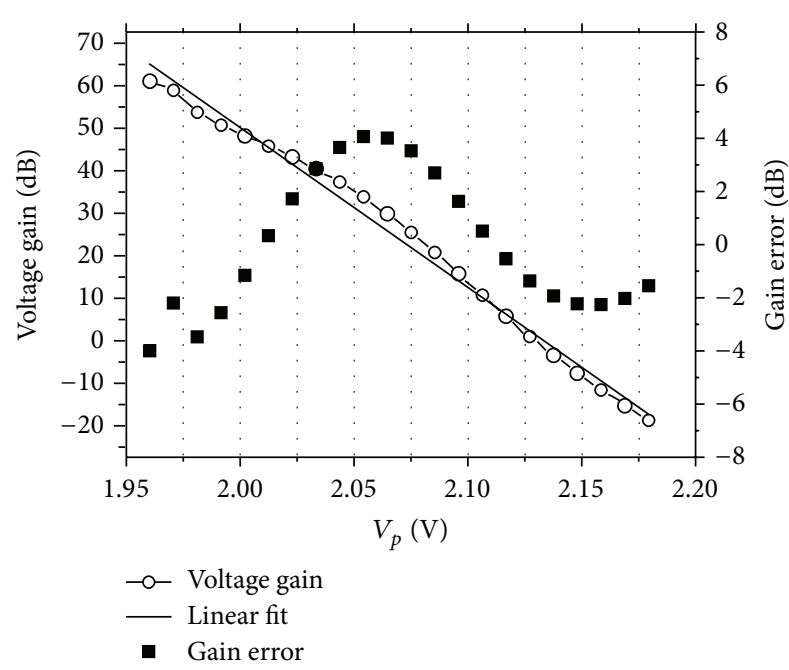

FIGURE 12: Voltage gain and gain linearity versus control voltage $V_{p}$.

of the second variable gain core is sensed by a RC LPF at low frequency and stored in the Miller capacitances. Following a high input impedance voltage amplifier using an NFET differential pair, a transconductance amplifier using an NPN differential pair transforms the input voltage into differential current which is injected back to the output of the transadmittance stage of the first gain core to adjust the output DC offset voltage. This DC offset loop is designed to have a low pass frequency response with a cut-off frequency of $800 \mathrm{kHz}$.

As mentioned in Section 2, the hybrid current-steering cell has the same relationship between gain and control voltage with the conventional current-steering cell. Thus a curvature linearization circuit [11] designed for currentsteering cell is employed to the gain cores in two stages to make the gain control linear-in-dB.

\section{Postlayout Simulation Results}

The proposed architecture is implemented in HHNEC's $0.18 \mu \mathrm{m}$ SiGe HBT BiCMOS technology which integrates $0.2 \mu \mathrm{m}, 1.8 \mathrm{~V} \mathrm{BV}_{\mathrm{CEO}}, 110 \mathrm{GHz} \mathrm{f}_{\mathrm{t}}$ SiGe HBTs, together with $0.18 \mu \mathrm{m}, 1.8 \mathrm{~V}$ Si CMOS devices. The layout of the chip is shown in Figure 10. The VGA occupies $280 \mu \mathrm{m}$ by $140 \mu \mathrm{m}$ and total chip with testing pads takes an area of $800 \mu \mathrm{m}$ by $550 \mu \mathrm{m}$. Under the $3.3 \mathrm{~V}$ power supply, the VGA consumes $9.2 \mathrm{~mA}$ excluding the output buffer which draws $8 \mathrm{~mA}$.

The frequency response of the proposed VGA is shown in Figure 11 with control voltage $V_{p}$ ranging from $1.96 \mathrm{~V}$ to $2.18 \mathrm{~V}$. At the maximum gain of $61 \mathrm{~dB}$, the simulated $3-\mathrm{dB}$ bandwidth is $2.5 \mathrm{GHz}$, and at the minimum gain of $-19 \mathrm{~dB}$, the bandwidth is $2.0 \mathrm{GHz}$. Thanks to the broadband character of the Cherry-Hooper amplifier, the gain-bandwidth product at the maximum gain can achieve a quite competitive value of $2805 \mathrm{GHz}$. Figure 12 shows the voltage gain and linear-in$\mathrm{dB}$ characteristics. The gain error is $4 \mathrm{~dB}$ over $80-\mathrm{dB}$ gain range. The noise figure at maximum gain shown in Figure 13 is smaller than $15 \mathrm{~dB}$ over the entire band. The simulated input

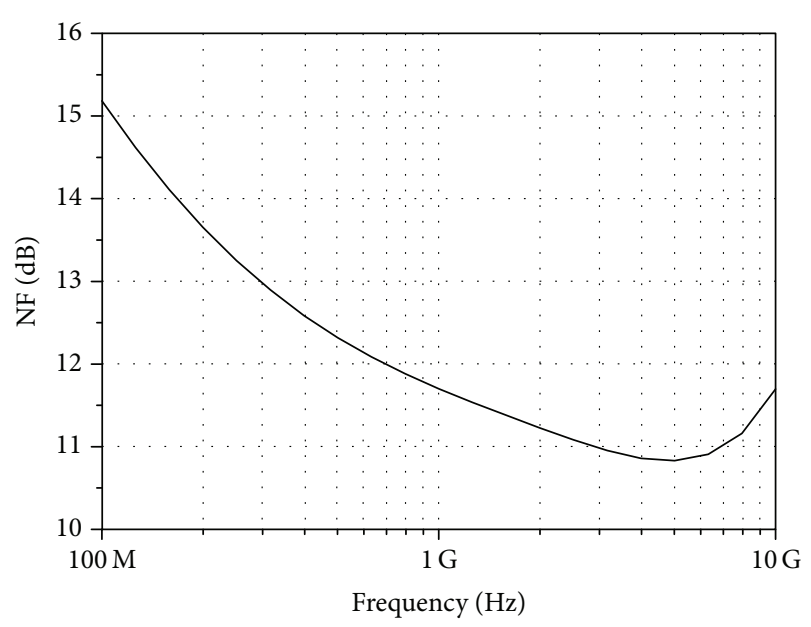

FIGURE 13: Noise figure at maximum gain.

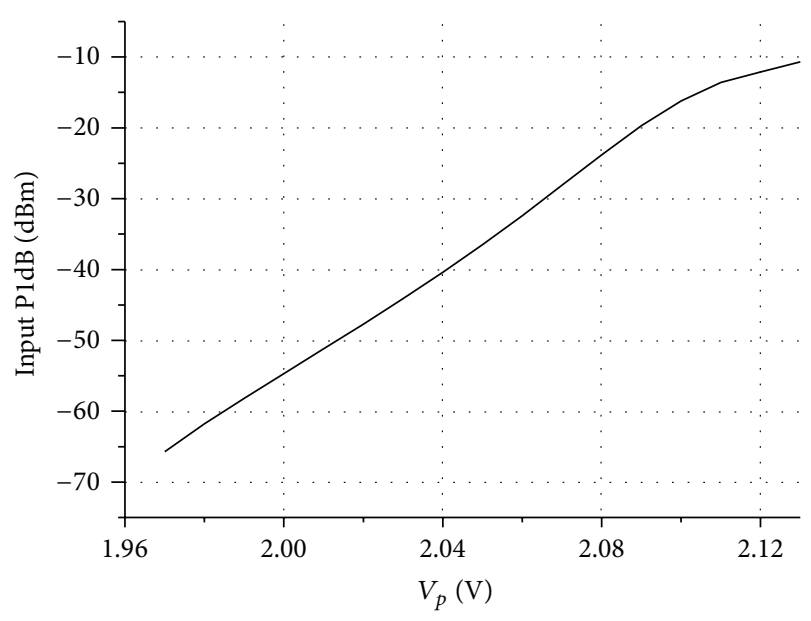

Figure 14: Input P1 dB versus control voltage $V_{p}$.

$\mathrm{P} 1 \mathrm{~dB}$ is $-10 \mathrm{dBm}$ at $-19 \mathrm{~dB}$ minimum gain and $-65 \mathrm{dBm}$ at $61 \mathrm{~dB}$ maximum gain as shown in Figure 14.

Table 1 compares the performance of the proposed VGA with other works and shows a competitive gain bandwidth product with the largest gain tuning range among other works.

\section{Conclusions}

The proposed VGA comprises two cascaded variable gain core, in which a hybrid current-steering current gain cell is inserted in the Cherry-Hooper amplifier to maintain a broad bandwidth while covering a wide gain range. The introduced hybrid current-steering cell can provide current transfer function equal to the conventional current-steering cell while maintaining a constant DC output current. Postlayout simulation results confirm that the proposed circuit achieves a $2 \mathrm{GHz} 3-\mathrm{dB}$ bandwidth with wide linear-in- $\mathrm{dB}$ gain tuning range from $-19 \mathrm{~dB}$ up to $61 \mathrm{~dB}$. The amplifier offers a competitive gain bandwidth product of $2805 \mathrm{GHz}$ at the maximum gain for a $110-\mathrm{GHz} \mathrm{f}_{\mathrm{t}}$ BiCMOS technology. 
TABLE 1: VGA performance comparison.

\begin{tabular}{|c|c|c|c|c|c|c|}
\hline & $\begin{array}{c}\text { Gain range } \\
(\mathrm{dB})\end{array}$ & $\begin{array}{c}\text { Bandwidth } \\
(\mathrm{GHz})\end{array}$ & $\begin{array}{c}\mathrm{GBP} \\
(\mathrm{GHz})\end{array}$ & $\begin{array}{l}\text { Power } \\
(\mathrm{mW})\end{array}$ & Technology & Linear-in- $\mathrm{dB}$ \\
\hline Wang et al. 2012 [8] & $-10 \sim 50$ & 2.2 & 700 & 2.5 & CMOS $90 \mathrm{~nm}$ & No \\
\hline Kumar et al. 2010 [2] & $-10 \sim 10$ & 4 & 12 & 9 & SiGe 0.18 um & No \\
\hline Manstretta and Dauphinee 2007 [4] & $-30 \sim 30$ & 1 & 32 & 250 & SiGe 0.18 um & No \\
\hline Jianhong et al. 2007 [5] & $-17 \sim 16$ & $0.4 \sim 0.8$ & 6 & 22 & CMOS 0.18 um & No \\
\hline Chang et al. 2009 [6] & $-10 \sim 17$ & 0.9 & 7 & 40 & SiGe 0.35 um & Yes \\
\hline This work & $-19 \sim 61$ & 2 & 2805 & 31 & SiGe 0.18 um & Yes \\
\hline
\end{tabular}

The amplifier core consumes $31 \mathrm{~mW}$ from a $3.3 \mathrm{~V}$ supply and occupies active area of $280 \mu \mathrm{m}$ by $140 \mu \mathrm{m}$.

\section{Conflict of Interests}

The authors declare that they have no conflict of interests regarding the publication of this paper.

\section{References}

[1] Agilent, "Wireless LAN at $60 \mathrm{GHz}$-IEEE 802.11ad explained," Application Note, 2012.

[2] T. B. Kumar, K. Ma, K. S. Yeo et al., "A DC to $4 \mathrm{GHz}$ fully differential wideband digitally controlled variable gain amplifier," in Proceedings of the Asia-Pacific Microwave Conference (APMC '10), pp. 2295-2298, Yokohama, Japan, December 2010.

[3] C. Liu, Y. P. Yan, W. L. Goh, Y. Z. Xiong, L. J. Zhang, and M. Madihian, "A 5-Gb/s automatic gain control amplifier with temperature compensation," IEEE Journal of Solid-State Circuits, vol. 47, no. 6, pp. 1323-1333, 2012.

[4] D. Manstretta and L. Dauphinee, "A highly linear broadband variable gain LNA for TV applications," in Proceedings of the IEEE Custom Integrated Circuits Conference (CICC '07), pp. 531534, San Jose, Calif, USA, September 2007.

[5] X. Jianhong, I. Mehr, and J. Silva-Martinez, "A high dynamic range CMOS variable gain amplifier for mobile DTV tuner," IEEE Journal of Solid-State Circuits, vol. 42, no. 2, pp. 292-301, 2007.

[6] C.-H. Chang, C.-F. Lee, and Y.-L. Tsou, "A wide-band low noise amplifier using cross-coupled technique with linear in $\mathrm{dB}$ gaincontrol," in Proceedings of the IEEE International Conference on Ultra-Wideband (ICUWB '09), pp. 251-254, September 2009.

[7] E. M. Cherry and D. E. Hooper, "The design of wide-band transistor feedback amplifier," Proceedings of the Institution of Electrical Engineers, vol. 110, no. 2, pp. 375-389, 1963.

[8] Y. Wang, B. Afshar, L. Ye, V. C. Gaudet, and A. M. Niknejad, "Design of a low power, inductorless wideband variable-gain amplifier for high-speed receiver systems," IEEE Transactions on Circuits and Systems I: Regular Papers, vol. 59, no. 4, pp. 696-707, 2012.

[9] C. D. Holdenried, J. W. Haslett, and M. W. Lynch, "Analysis and design of HBT Cherry-Hooper amplifiers with emitter-follower feedback for optical communications," IEEE Journal of SolidState Circuits, vol. 39, no. 11, pp. 1959-1967, 2004.

[10] H. Ishihara, "Variable gain amplifier circuit," US Patent 6177839, 2001.

[11] S. Aggarwal, A. Khosrowbeygi, and A. Daanen, "A singlestage variable-gain amplifier with $70-\mathrm{dB}$ dynamic range for
CDMA2000 transmit applications," IEEE Journal of Solid-State Circuits, vol. 38, no. 6, pp. 911-917, 2003. 

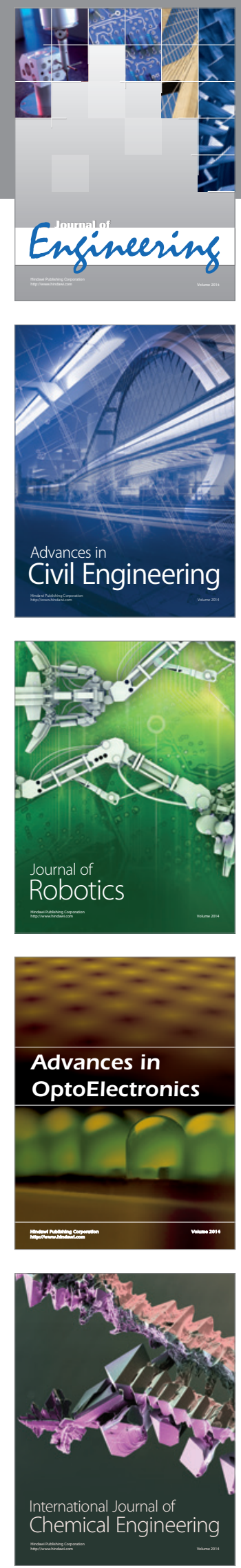

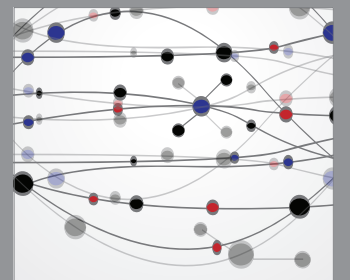

The Scientific World Journal
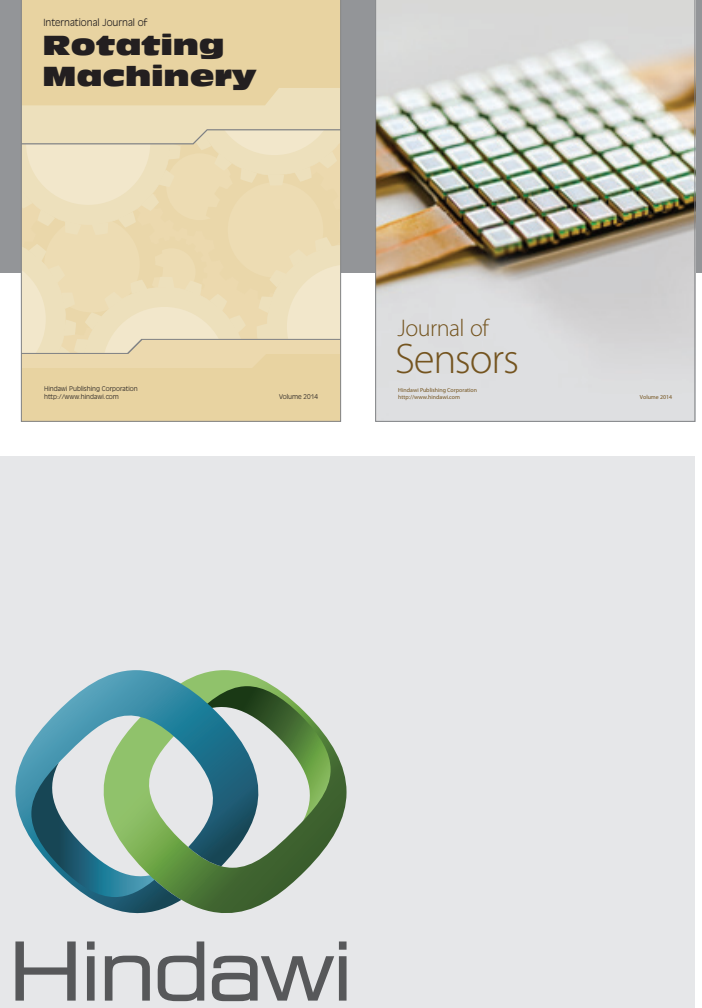

Submit your manuscripts at http://www.hindawi.com
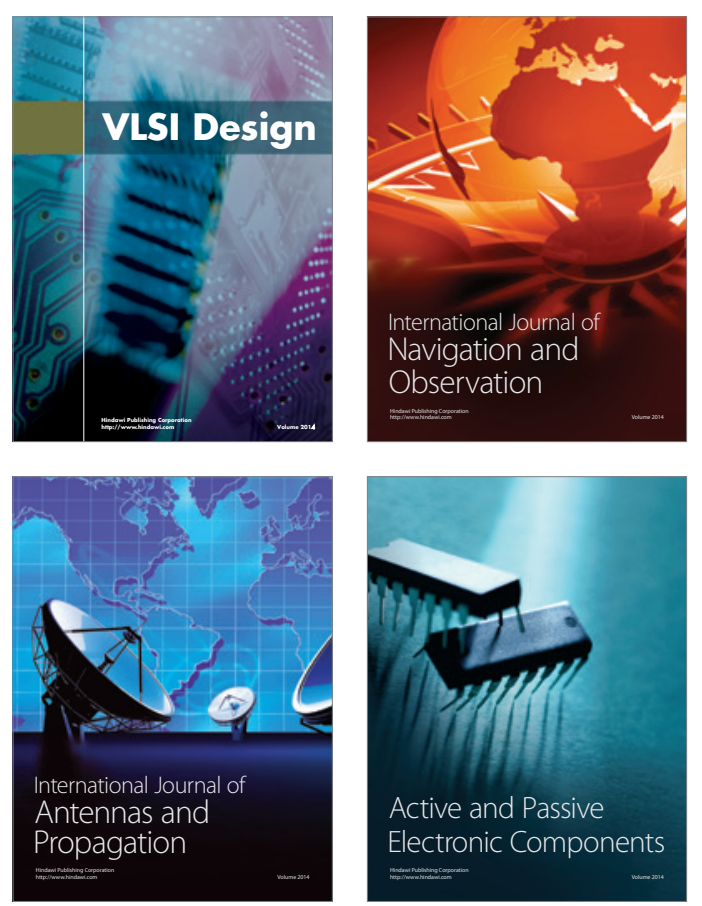
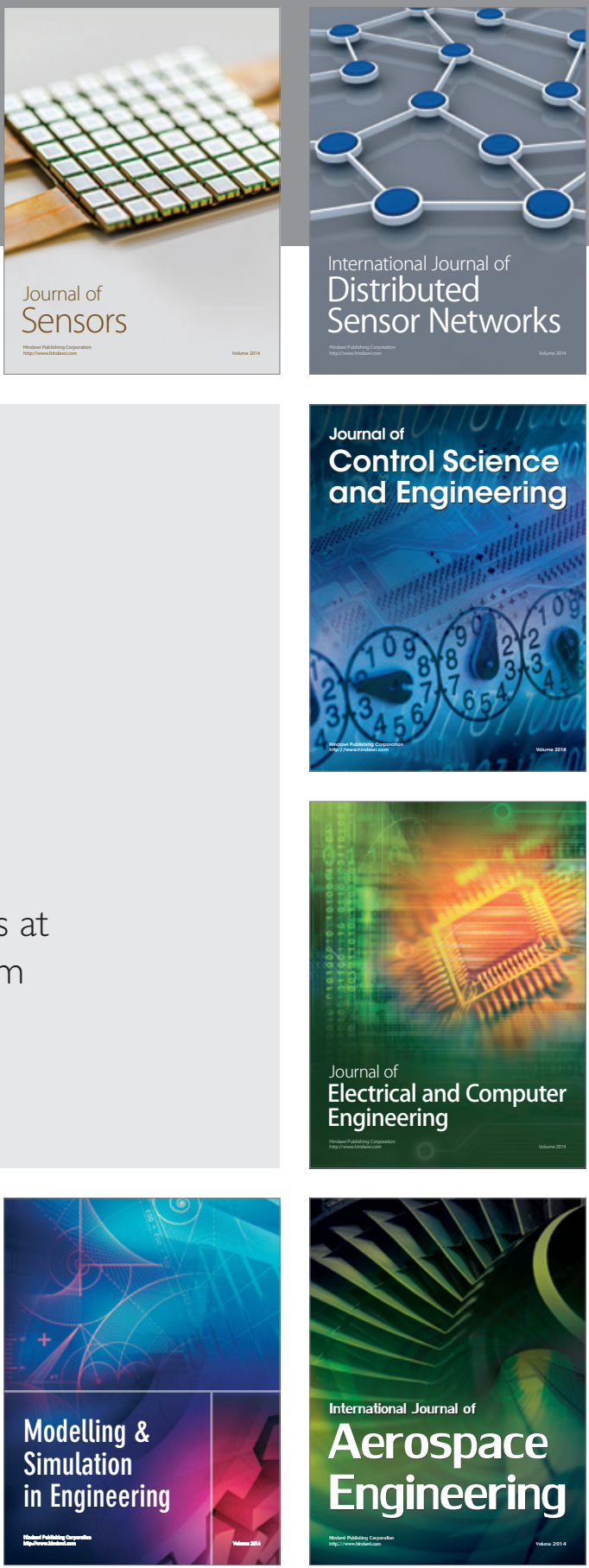

Journal of

Control Science

and Engineering
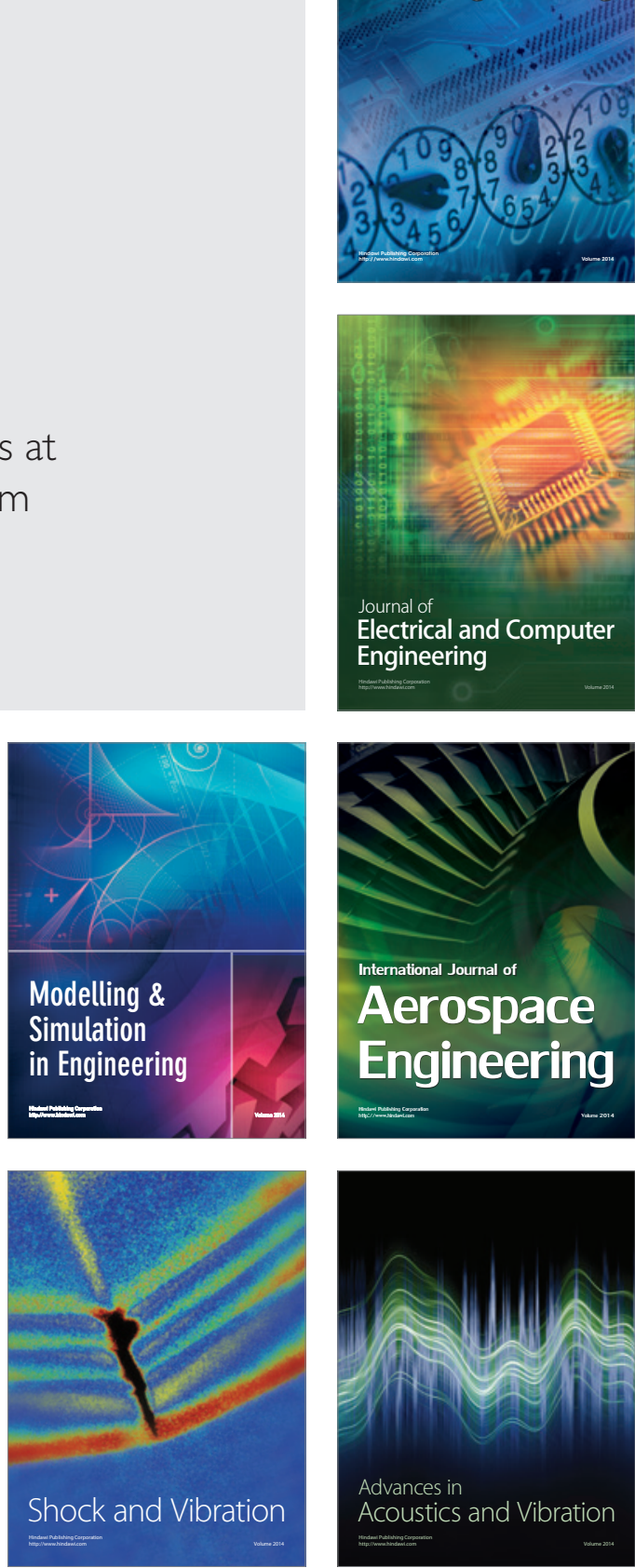